Research Article

\title{
A Cumulative Expansion Force-Finding Method for Suspension-Cable Truss Composite Structure
}

\author{
Lifan Huang $\mathbb{D}^{1,2,3}$ Bin Luo $\mathbb{D},{ }^{1,2,3}$ Mingmin Ding $\mathbb{D},{ }^{4}$ Chunshui Zhang $\mathbb{D}^{5}$, \\ and Yangjie Ruan (D), 1,2,3 \\ ${ }^{1}$ College of Civil Engineering, Southeast University, Nanjing 210096, China \\ ${ }^{2}$ National Pre-Stress Engineering Research Center, Southeast University, Nanjing 210096, China \\ ${ }^{3}$ The Key Laboratory of C\&PC Structures of the Ministry of Education, Southeast University, Nanjing 210096, China \\ ${ }^{4}$ College of Civil Engineering, Nanjing Forestry University, Nanjing 210000, China \\ ${ }^{5}$ Nanjing Yangtze River Urban Architectural Design Co., Ltd., Nanjing 210000, China \\ Correspondence should be addressed to Bin Luo; seurobin@seu.edu.cn
}

Received 21 September 2020; Accepted 12 December 2020; Published 29 December 2020

Academic Editor: Raffaele Landolfo

Copyright $\odot 2020$ Lifan Huang et al. This is an open access article distributed under the Creative Commons Attribution License, which permits unrestricted use, distribution, and reproduction in any medium, provided the original work is properly cited.

\begin{abstract}
Suspension-cable truss composite structure is a new type of cable-strut structure which combines the conventional cable structure with the rigid truss. By laying rigid roofing slabs, this composite structure offsets most effect of the wind suction, reduces the axial force of the stable cables, and reduces the large vertical displacement effectively when compared with conventional cable trusses. For this new structure, the deformation relevance between adjacent substructures results in a nonindependent and stable union. To effectively and precisely find the cable forces of a suspension-cable truss composite structure for the construction completion state, a proper optimization order and a suitable selection of the substructures are necessary. In this paper, the structural mechanical characteristics of the suspension-cable truss composite structure are introduced at first, to reveal the force transmission path between adjacent substructures. Secondly, the cumulative expansion force-finding method (CEFM) is proposed to obtain the optimal mode of the cable force distribution with a suitable operational efficiency. A numerical example is introduced and analyzed to verify the accuracy and feasibility of this method afterwards. The results show that CEFM could find out the optimal cable force distribution of the suspension-cable truss composite structure, with a geometry shape of whole structure and a rational stress level of all the components.
\end{abstract}

\section{Introduction}

The prestressed cable truss is a typical cable-strut structure [1], which is generally composed of two prestressed cables, several short compression struts, and a steel roof grid. The combination of the prestressed cables and the steel grid gives the overall structure external rigidity and make it an entire to resist relatively larger external load than conventional steel roofs. Due to its large clearance and strong spanning capacity, cable trusses have been widely used in many airports and exhibition centers, such as Shenzhen Bao'an Stadium (Figure 1(a)) [2], Ukraine National Sports Complex "Olympiysky" (Figure 1(b)), and Yueqing stadium (Figure 1(c)) [3]. Moreover, the bottom cable-strut system could be arranged in two orthogonal directions, which makes the whole structure suitable for rectangular, circular, elliptical, or other complex structural forms.

Different from rigid structures (i.e., single-layer latticed shell or suspend domes) [4-6], a cable truss is mainly composed of flexible cables, which directly bear roof loads, and compression struts, which exist in the ocean of tension cables [7]. The sectional stiffness of the cable itself is very small, leading to large out-of-plane deformation of the cables under small external loads. However, if pretension forces of the cables have been built in advance, a relatively larger overall stiffness will be established in the cable-strut system, which will reduce the overall displacement of the overall structure. Therefore, the static response of a cable truss is in 


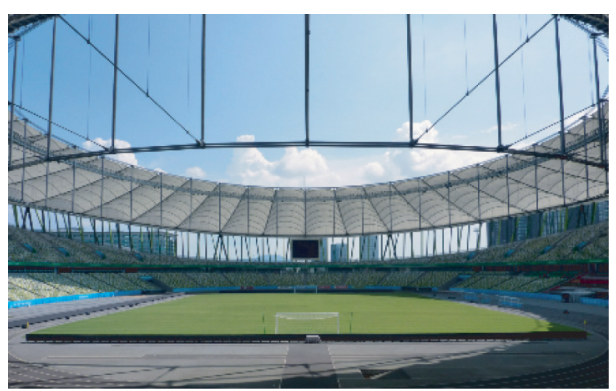

(a)

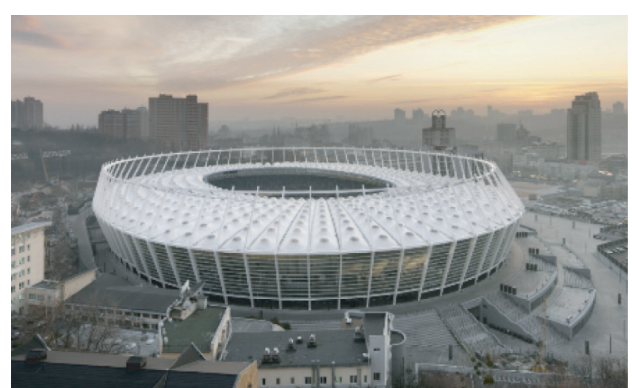

(b)

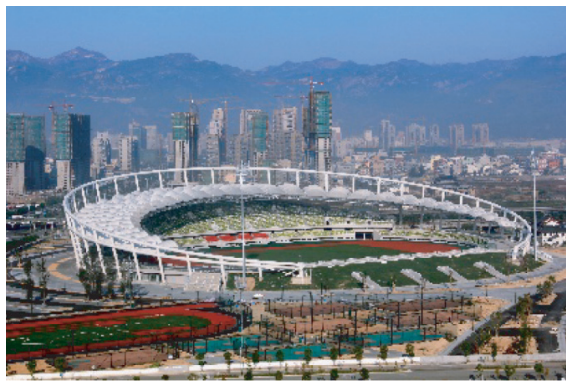

(c)

Figure 1: Typical projects of cable truss. (a) Shenzhen Bao'an stadium. (b) Ukraine National Sports Complex "Olympiysky”. (c) Yueqing stadium.

some means determined by the prestress level of the bottom cable-strut system. For flexible tension structures, the prestress level in the cable system determines the geometric stiffness, the bearing capacity, and the applicability of the structure. If the prestress level is too low, it is not conducive to form the structural stiffness, and the bearing capacity is also insufficient. On the contrary, if the prestress level is too high, the reaction forces of the supports will be very large, which will bring about unnecessary consumption of the material dosage.

In recent years, extensive morphological studies have been conducted on cable-strut structures. Based on the Maxwell criterion [8] and the linear algebra tool, Pellegrino and Calladine conducted research on the self-stress mode of the cable dome system. After that, Pellegrino and Calladine put forward the theory of balance matrix in 1984, which laid the foundation for the analysis of the internal force of the strut system structure and successfully solved the balance equation and the self-stress mode of the strut system result by using the singular value decomposition method [9]. Kangwai and Guest determined the self-stress mode and mechanism of Geiger-type cable dome by using the block decomposition balance matrix and then proposed the feasible prestress concept of a tensegrity structure. Furthermore, by taking the minimum sum of the initial self-stress mode combination coefficient of the structure as the goal and using the linear programming method, they carried out the optimal design of a cable-strut structure [10]. Based on the principle that all cables are under tension, all struts are under compression; the concept of overall feasible prestress was put forward by using the self-stress mode, obtained by the balance matrix method. Moreover, the integral feasible prestress equation was solved by using the haushold transformation to obtain the overall feasible prestress of the cable dome structure under the single self-stress mode [11]. By using the theory of structural equilibrium matrix and the algorithm of algebraic singular value decomposition, Lin et al. presented the objective selection optimization method through the decomposition transformation and combination operation of a structural modal matrix, which realized the feasible prestress distribution solution of cable-strut tension structure system with multiple self-stress modes conveniently and successfully applied this method to the cable truss structure in annular space [12]. What's more, Zhou et al. modified the existing double singular value decomposition method using the proposed scheme that could provide an initial group classification being helpful to decrease the undesirable numbers of prestress states, which could be proved effective and accurate in saddle-shaped roof structure [13]. In addition, considering the symmetry of the structure, Dong and Yuan et al. proposed a simple algorithm for the initial internal force finding of honeycomb-type cable dome on the basis of the node balance theory [14]. In the field of finding form and force simultaneously, the force density method and dynamic relaxation method play an important role [15]. Schek firstly introduced the concept of force density to deform the node balance equation, turning the complex solution of nonlinear equation group into an independent solution of the first-order equation group, which largely reduces the complexity of calculation [16]. Vassart and Motro et al. brought forward analytical method after a lot of calculation and analysis on the basis of the force density method. They solved the balance matrix by using the Gauss elimination method, which solved the problem of 
rank deficiency finding of the node balance matrix of the force density method and takes the lead in applying the force density method to the form-finding research of the tensegrity structure [17]. Based on the research of Schek and Motro, Zhang and Ohsaki proposed the self-adaptive density method based on the eigenvalue analysis and spectral decomposition of the force density matrix. In the iterative calculation, the force density matrix was automatically adjusted to constantly find the required rank deficiency value, which solved the problem that the force density method was difficult to be applied to the structures with massive cable and strut elements [18]. Based on the selfadaptive density method, Tran and Lee adjusted the iterative strategy, gave the iterative calculation method which could be applied to the super stable structure, and successfully carried out the form finding analysis on the cable-strut system and the tensegrity structure $[19,20]$. Guo et al. introduced the idea of "Firstly, find the forces of cables through the determined form of the cable-net. Secondly, find the actual form through the cable forces found in the first step." into the force density method, which solved the problem of poor convergence occurred in the force density method and successfully realized the form-finding analysis of saddle-shaped cable-net structure [21]. More recently, Ding and Luo introduced the operation principle of the nonlinear force method into the dynamic relaxation method and proposed the nonlinear dynamic finite element theory [22].

The above studies are mainly focused on the circular cable-strut structures with the light membrane surface, with less attention on cable truss structures, especially the suspension-cable truss composite structure with a heavy roofing system. Different from the network structures, a unit of the suspension-cable truss composite structure is composed of two mutually perpendicular substructures in the horizontal direction; these two substructures share the load of the upper roof, and both are need to be pretensioned. For this kind of composite structure, a proper initial cable force distribution is the key point that needs to be obtained, while existing studies mainly lie in the rigid structure [23].

Considering these aspects, the cumulative expansion force-finding method (CEFM) is proposed in this paper to find the initial cable force distribution of the suspensioncable truss composite structure. Due to the fact that adjacent cables are closely related in the process of force finding; it is difficult to find the initial forces of the cables one by one. CEFM divides the cables into several substructures at first, finds the forces of cables in each substructure afterwards, and combines the substructures into a whole. At last, the suspension-cable truss composite roof of Shijiazhuang International Exhibition Center is taken as a calculation example, the target of force-finding analysis is given, and the iterative process is carried out. The results proved the feasibility and accuracy of the theory.

\section{Configuration of Suspension-Cable Truss Composite Structure (SCTCS)}

A conventional cable truss structure is made of upper loadbearing cables, bottom stable cables, and middle struts (or cables). The load-bearing cables are the main components to bear external roofing loads, while the stable cables are mainly used to ensure the stability of the load-bearing cables and resist the wind loads. Therefore, whether the layout of the overall structure is parallel or circular, out-of-plane auxiliary members are needed to form the spatial form of cable trusses. Different from rigid grids, the stiffness of conventional cable truss is primarily attributed to pretension. The level of prestress not only affects the geometric configuration but also determines the applicability and load-bearing capacity of the entire structure. Wang et al. [24] indicated that the nodal vertical displacement increases linearly with an increasing, uniform external load. In this case, the controlling factor of the conventional cable truss is the large nodal deformations of the structure, not the material strength of the components, leading to a waste of the mechanical properties of the high-strength cables and struts.

In contrast, a SCTSC consists of a single-layer single curved surface suspension structure and a bottom cable-strut system, as shown in Figure 2. The bottom cable-strut units could be divided into two main parts: the main bearing structure in the longitudinal direction, and the secondary bearing structure in the transverse direction. External loads from the upper roof would be transferred to a single-layer single curved surface suspension structure at first, then to the secondary bearing structure, and to the main bearing structure afterwards. Consequently, with the addition of the bending stiffness contributed by the single-layer single curved surface suspension structure, an SCTCS can produce a relatively higher bearing capacity with the same pre-stress level than conventional cable trusses. Meanwhile, the existence of cable truss can effectively improve the out-of-plane stability of the single-layer suspension structure, which generates enough geometric stiffness for the overall structure to bear the heavy roofing panels laid on the top and could further improve the overall stiffness to reduce the overall deformation.

The main bearing structure of SCTSC is a two-dimensional plane structure, which is composed of main suspension cables (MC1), outer inclined cables (MC2), landing vertical cables (MC3), upper chord pipes (UCP), lower chord pipes (LCP), self-anchor stocks (SAS), vertical struts (VS), and A-shaped pillars, as displayed in Figure 3. The detailed description of these components is listed as follows:

(1) A-shaped pillar is a concrete-filled steel tube structure, with the bottom fixed to the foundation, and each main bearing structure has two A-shaped supporting pillars, as shown in Figure 3(b).

(2) MC1 transfers the roof load from the cable truss to the top of the A-shaped pillars. The horizontal component of tension force in $\mathrm{MC} 1$ is balanced by the outer inclined cable; the vertical component of inclined cable force is balanced by the landing vertical cable, while the horizontal component of inclined cable force is balanced by self-anchored stock.

(3) VS, illustrated in Figure 3(c), is a box-sectional component, which connects the UCPs, the LCPs, the middle SASs, and the main suspension cables. They are also part of the main load-bearing components that transmit the loads from the cable truss to the main suspension cables. 


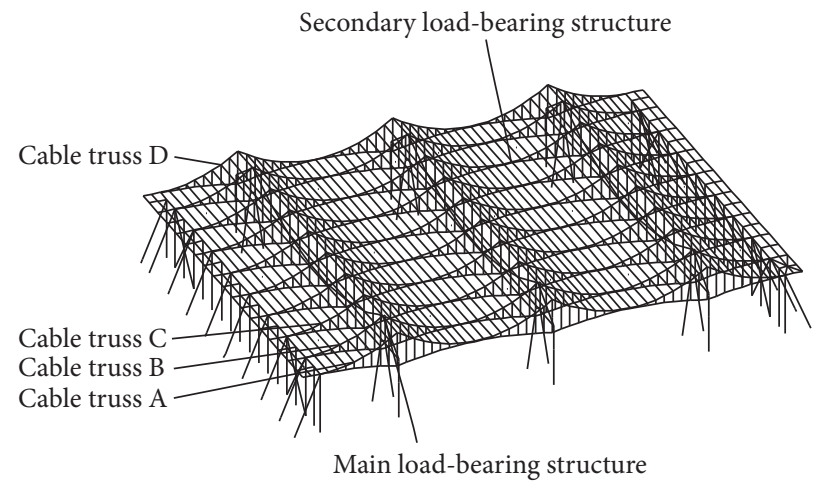

Figure 2: Axonometric drawing of the SCTC.

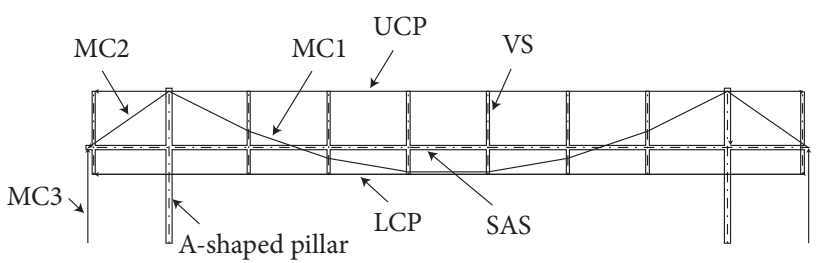

(a)

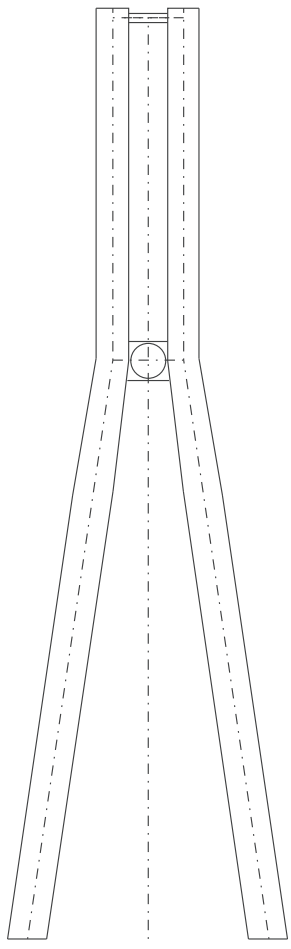

(b)

FIgURe 3: Continued. 


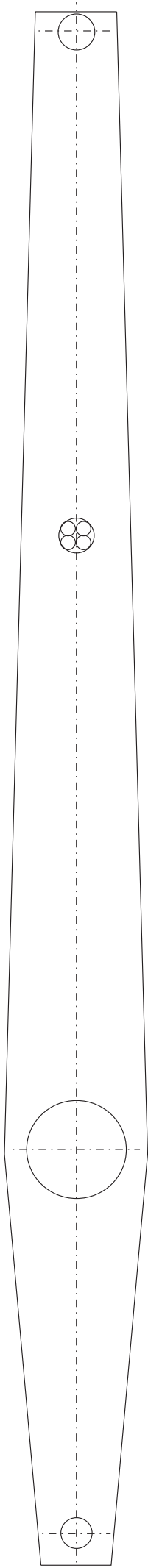

(c)

FIGURE 3: Composition of main load-bearing structure. (a) Main load-bearing structure. (b) A-shaped pillars. (c) Vertical struts. 
(4) UCPs, LCPs, and SASs are all round-sectional tubes. Among these three members, SASs connect the lower end of the outer inclined cable at both ends of the main bearing structure to balance the horizontal component of the outer inclined cable force and have the largest dimension, while the sizes of UCPs and LCPs, which do not directly bear loads are smaller.

The secondary load-bearing structure (Figure 4) is a cable truss structure, which consists of load-bearing cables (C1), stable cables (C2), slings (C4), side inclined cables (C3), side columns, and swing columns. According to the direction, external loads can be divided into the vertical downward load (such as self-weight of the components) and vertical upward load (such as wind suction load). The secondary bearing structure can be divided into three parts: load-bearing cable system, stable cable system, and balanced cable-strut system. The detailed description of these components is listed as follows:

(1) Load-bearing cable system is a kind of catenary suspension cable (i.e., the top chord cable of the cable truss), which is designed to bear vertical downward loads. External roof loads could be effectively transferred to the main load-bearing structure through $\mathrm{C} 1$ with its horizontal component balanced by the landing inclined cable on the outside.

(2) Stable cable system includes a convex stable cable and vertical slings, which bears part of upward wind load and improves the stability of load-bearing cable.

(3) Balanced cable-strut system includes the side columns and the side inclined cables; they are designed to balance the horizontal components of both the load-bearing cable and the stable cable. The side columns are a kind of compression rod, constrained by the bottom-hinged ends.

Furthermore, due to that, the resultant force of the wind suction load is straight up, while the self-weight of the roofing plates is straight down; heavy rigid roofing panels could be selected for SCTCS to offset most of the upward wind load and reduce the burden of the stable cable system. Therefore, the weight of heavy load roof panels is an important factor, which makes a large impact on the line shape of the entire structure.

\section{The Cumulative Expansion Force- Finding Method}

According to the characteristics mentioned above, deformation of each substructure of SCTCS will influence other ones, which means that there is not a single independent and stable substructure for the SCTCS. For example, the main load-bearing structure needs the secondary load-bearing structure to maintain its out-of-plane stability. Meanwhile, the secondary load-bearing structure is connected to the main load-bearing structure, and the load-bearing cables, stability cables, side columns, and landing cables of the main load-bearing structure are interdependent to maintain the balance. Thus, multiple force-finding objectives should be set to guarantee the accuracy of finding pretension distribution in each substructure and to avoid the chaotic phenomenon of cable force distribution in the force-finding process.

To achieve the goal of performing force-finding analysis to find the completed construction state of the SCTCS, the cumulative expansion force-finding method (CEFM) based on the fractional-step finite-element method [25] is introduced. Different from existing studies, the geometric relationship of the structure itself and the force transfer path combined with the optimization order of the cable forces of each substructure are fully considered in CEFM. The analysis steps of the present method are as follows:

(1) Define the coordinates of all the structural nodes in the construction completion state. Then, built the finite element model, according to the construction completion state. Apply the gravity, other necessary loads, and corresponding constraints to the boundary nodes. Define the iterative convergence conditions.

(2) Substructure division and solution order, as illustrated in Figure 5:

Step 1. Constrain the vertical displacement $U_{z}$ and horizontal displacement $U_{x}$ (i.e., along the direction of the secondary bearing structure) of the upper and lower nodes of the main bearing struts. Define that the vertical displacement of node $\mathrm{A}$ and node $\mathrm{B}$ (i.e., the nodes in the middle of the cable span), as shown in Figure 5(a), $U_{z \mathrm{~A}}$ and $U_{z \mathrm{~B}}$ to be 0 as the goal to perform the force-finding analysis of the cable system $\mathrm{C}_{b}$ and $\mathrm{C} 2_{b}$.

Step 2. Release the horizontal constraints of the main bearing structure and constrain the horizontal displacement of the upper and lower nodes of the side columns in the direction of the secondary bearing structure. Take the horizontal displacement of the upper and lower nodes C, D, E, and F of the main bearing structure struts to be 0 (i.e., $\left.U_{x \mathrm{C}}=U_{x \mathrm{D}}=U_{x \mathrm{E}}=0\right)$ as the goal to conduct the forcefinding analysis of the cable system $\mathrm{C}_{a}$ and $\mathrm{C} 2_{a}$.

Step 3. Release the horizontal constraints of the side columns. Take the horizontal displacement of the upper-end nodes $\mathrm{G}$ and $\mathrm{H}$ of the side columns to be 0 (i.e. $U_{x \mathrm{G}}=U_{x \mathrm{H}}=0$ ) as the goal to carry out the forcefinding analysis of the cable system C3.

Step 4. Release the vertical constraint of the main bearing struts and constrain the horizontal displacements of the top nodes of the A-shaped pillars along the direction of the main bearing structure. Take the average vertical displacement of the top node of the main bearing structure struts to be 0 as the goal to carry out the force-finding analysis of the cable system MC1.

Step 5. Release the horizontal constraints of the A-shaped pillars and constrain the vertical displacement of the end node of the anchor rod. Take the horizontal displacement of the top nodes $c$ and $d$ 


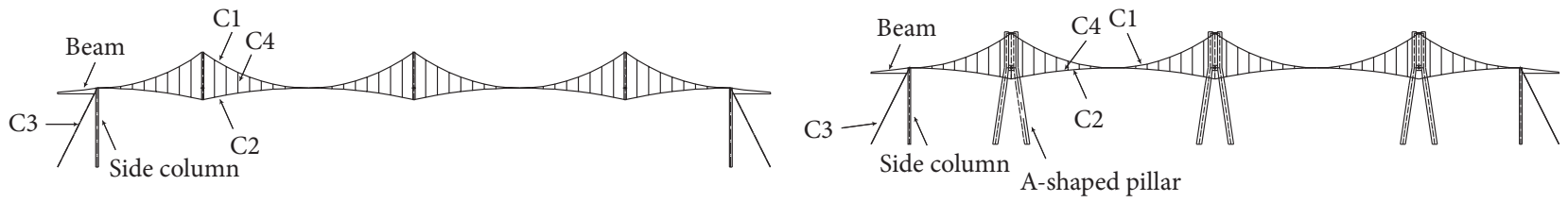

(a)

(b)

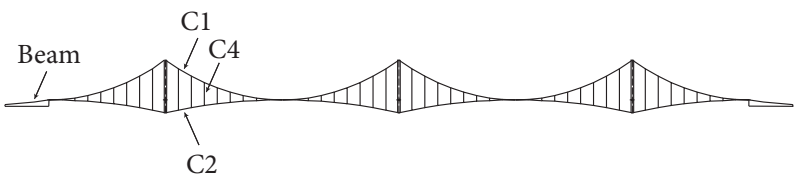

(c)

Figure 4: Composition of secondary load-bearing structure, (a) cable truss A and C, (b) cable truss B, (c) cable truss D.

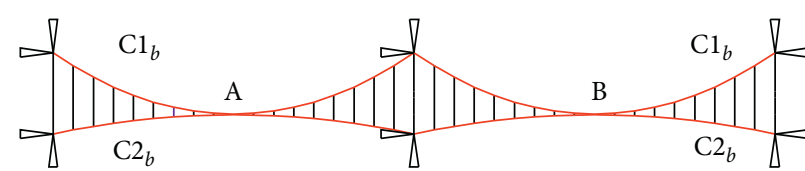

(a)

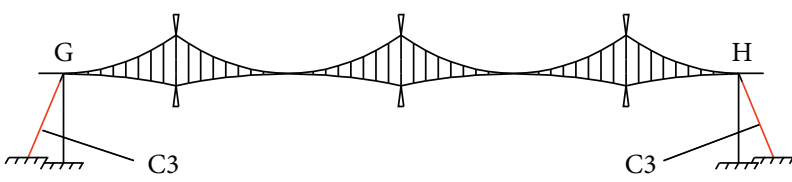

(c)

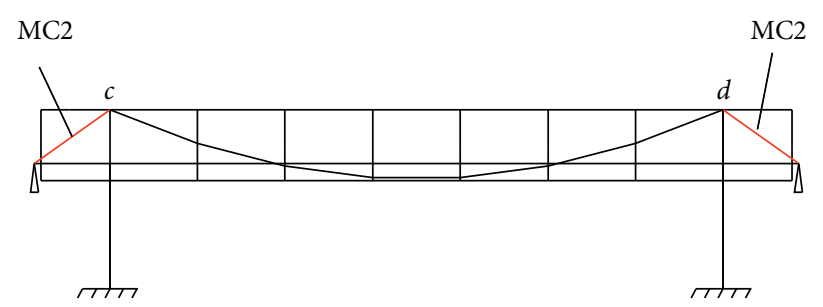

(e)

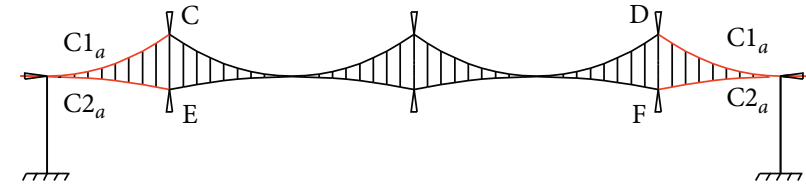

(b)

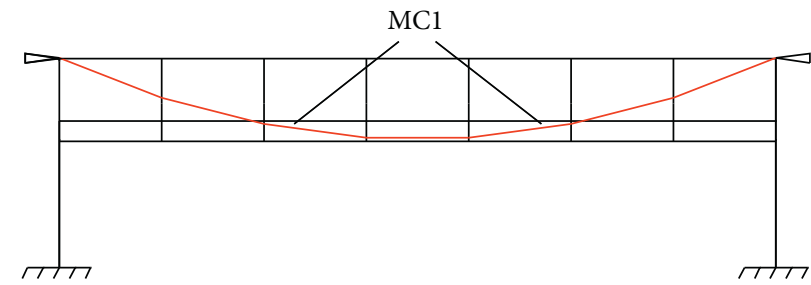

(d)

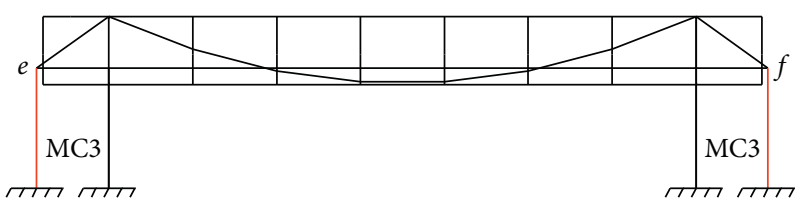

(f)

Figure 5: Operation process of substructures: (a) step 1, (b) step 2, (c) step 3, (d) step 4, (e) step 5, and (f) step 6.

of the A-shaped pillars to be 0 (i.e., $U_{y c}=U_{y d}=0$ ) as the goal to carry out the force-finding analysis of the cable system MC2.

Step 6. Release the vertical constraints of the selfanchored stocks and take the vertical displacements of the end nodes $e$ and $f$ of the self-anchored stocks to be 0 (i.e., $U_{z e}=U_{z f}=0$ ) as the goal to carry out the force-finding analysis of the cable system MC3.

(3) Iterative calculation of substructure:

Preparation: apply a set of equivalent temperature groups $\left[\Delta T_{1}\right],\left[\Delta T_{2}\right], \ldots,\left[\Delta T_{k-1}\right]$, and $\left[\Delta T_{k}\right]$ to the corresponding cables. Among them, temperature groups 1 to $(k-1)$ are calculated from the distribution of balanced cable forces in substructure 1 to $(k-1)$ after the completion of force finding through equation (2). And if the first substructure is analyzed, this step is skipped.
First iteration: apply a group of equivalent temperatures $\left[\Delta T_{k}^{1}\right]$ to the $k^{\text {th }}$ substructure, meanwhile the corresponding constraints for the $(k-1)$ substructure are released. The nonlinear finite element analysis solution is carried out to obtain the target response value of the substructure (the target response value could be deformation, stress, and cable force. In this paper, the deformation value is taken as the target response value). The convergence conditions set in advance are compared, as shown in the following equation:

$$
\left|U^{k 1}\right| \leq U_{\text {lim }}, \quad \text { where } k=1,2,3 \ldots
$$

If the convergence condition is satisfied, the iteration is terminated. If not, the second step of iteration is started.

Second iteration: apply the equivalent temperatures $\left[\Delta T_{k}^{2}\right]$ transformed from the cable force distribution 
generated by iteration 1 through equation (2) to the $k^{\text {th }}$ substructure. Then, carry out nonlinear finite element analysis to obtain the target response value of the substructure, which is compared with the convergence conditions set in advance, as shown in equation (3). If the convergence conditions are met, the iteration is completed. If the convergence conditions are not met, the third step of iteration is started.

$$
\begin{gathered}
\Delta T_{k}^{i}=\frac{T_{k}^{i-1}}{\alpha_{k} E_{k} A_{k}}, \quad \text { where } k=1,2,3 \ldots, \\
\left|U^{k 2}\right| \leq U_{\text {lim }}, \quad \text { where } k=1,2,3 \ldots
\end{gathered}
$$

The $i^{\text {th }}$ iteration: apply the equivalent temperatures $\left[\Delta T_{k}^{i}\right]$ transformed from the prestress distribution generated by iteration $(i-1)$ through equation (2) to the $k$ substructure. Then, carry out nonlinear finite element analysis to obtain the target response value of the substructure $U^{k i}$. If $U^{k i}$ meets the convergence condition expressed by equation (4), the target initial equilibrium cable force distribution of the $k$ substructure $\Delta T_{k}=\Delta T_{k}^{i}$. If not, the $(k+1)$ step of iteration is started.

$$
\left|U^{k i}\right| \leq U_{\text {lim }}
$$

After the iterative force finding of all substructures, the nonlinear finite element solution of the whole structure is carried out to obtain a group of balanced cable forces, which is the objective initial balanced cable force distribution that we have been seeking for.

\section{Calculation Example}

4.1. Summary of the Structure. Shijiazhuang International Exhibition Center is located in Zhengding new area, northeast of the center of Shijiazhuang, China (Figure 6). The planned land area of the project is 64.4 hectares, with a total construction area of $356000 \mathrm{~m}^{2}$. This project is composed of three standard exhibition halls (A, C, and E), one large exhibition hall (D), and one conference center (B) in the core area. The total length is about $648 \mathrm{~m}$, and the total width is about $352 \mathrm{~m}$.

The main structure system of the exhibition halls (i.e., A, $\mathrm{C}, \mathrm{D}$, and $\mathrm{E}$ ) on the ground is a suspension-cable truss composite structure. The overall structure includes main load-bearing structure, secondary load-bearing structure, purlin structure, and roof panel. The main load-bearing structure is self-anchored suspension structure, the secondary load-bearing structure is cable truss structure, and the purlin structure includes purlins, supports, and braces.

The main structure of hall D has a transverse length of $306 \mathrm{~m}$ and a longitudinal length of $137.5 \mathrm{~m}$. The roof cornice elevation is $+18.000 \mathrm{~m}$, the ridge structure elevation is $+28.650 \mathrm{~m}$, and the clear indoor structure height is $13 \mathrm{~m}$. The roof supporting system is composed of six A-shaped pillars in the middle and 18 side supporting columns at the end of the exhibition hall. The transverse space between A-shaped pillars is $108 \mathrm{~m}$, and the longitudinal space is $105 \mathrm{~m}$. The

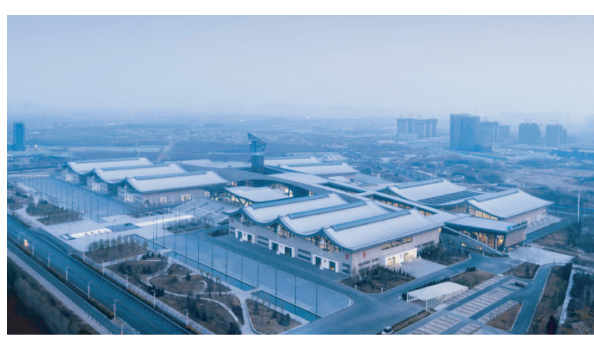

Figure 6: Completion of the project.

distance between the edge supporting pillars at the end of the exhibition hall and the A-shaped pillars is $36 \mathrm{~m}$, and the distance between the edge supporting pillars is $15 \mathrm{~m}$.

\subsection{Analysis Software, Models, and Parameters}

(1) Analysis software: finite element analysis software ANSYS 12.0.

(2) Analysis model: establish the finite element model according to the ideal model under the dead load.

(3) Analysis load:

analysis load $=$ structure weight + main purlin weight + roof system weight.

In addition, the weights of cable clamps and cable heads are calculated, respectively, according to the dimensions and added in the form of node loads considering the additional coefficient of node selfweight of 1.05 (note: the total weight of the main purlin and roof system is $1 \mathrm{kN} / \mathrm{m}^{2}$ ).

(4) Support constraints: the supports at the bottom of A-shaped pillars are fully constrained, and the rest are hinge constraints.

(5) Elastic modulus: the elastic modulus of steel members is $2.06 \times 10^{5} \mathrm{MPa}$, and the elastic modulus of cables is $1.6 \times 10^{5} \mathrm{MPa}$.

4.3. Force-Finding Target. Generally, the optimization of the initial pretension forces of the cables should meet the following requirements:

(1) The whole structure must reach the required configuration after the initial pretension forces are applied.

(2) The size and distribution of the prestress level should fulfill the requirements of member stresses and deformations of the structure under external loads, which means the requirements of ultimate limit state and normal use limit state, specified in the Eurocode 3(EN 1993-1-11:2006) [26] should be met.

(3) The pretension forces of the cables, with the same location and specifications in different substructures, should be the same. 
TABLE 1: Goal of the construction completion.

No. of exhibition Goal of the construction completion

(1) The average value of the vertical displacement of the top node of the main bearing structure is close to $0 \mathrm{~mm}$.

(2) The stress level of the main bearing structure should be as low as possible.

Exhibition D (3) The vertical displacement of the self-anchored stocks' ends of the main bearing structure is close to $0 \mathrm{~mm}$.

(4) The midspan vertical displacement of the secondary bearing structure is close to $0 \mathrm{~mm}$.

(5) The stress level of the secondary loadbearing structure should be as low as possible.

In this paper, "construction completed state" is defined as cable tensioning, main purlin and roof installation, support unloading, and swing column installation are completed.

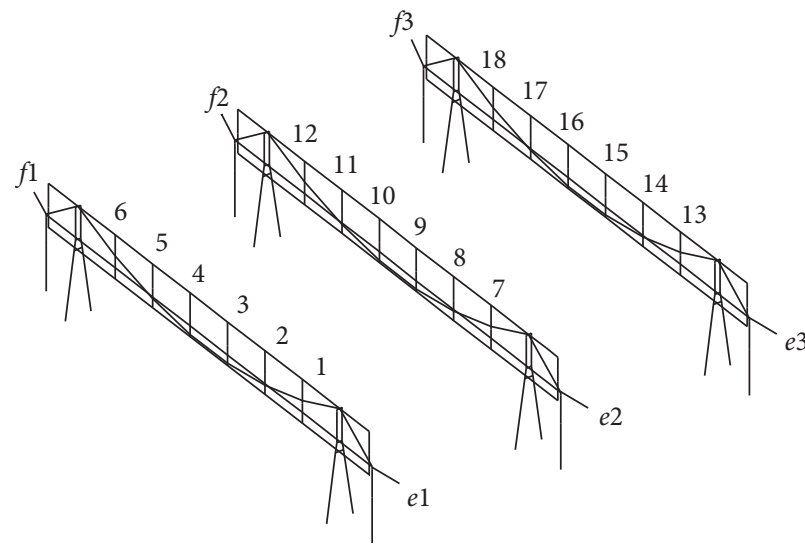

(a)

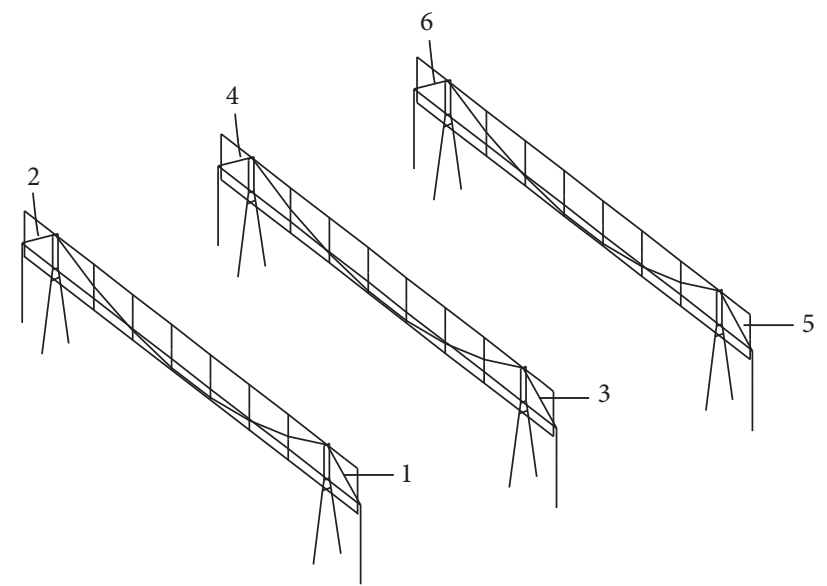

(b)

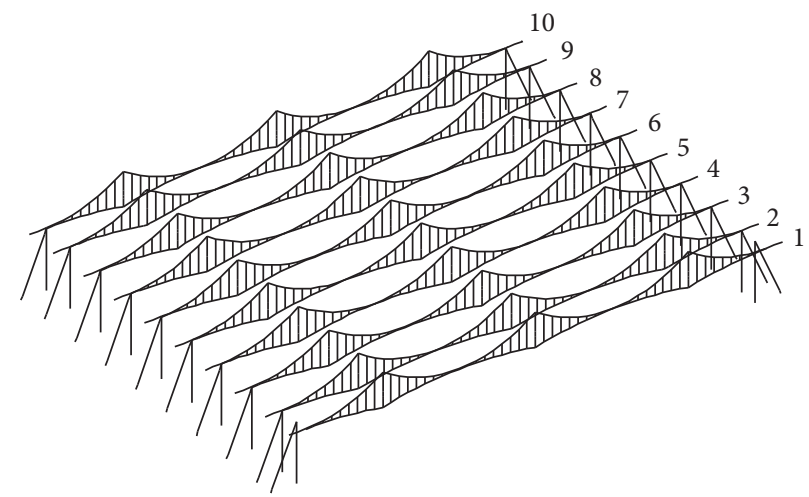

(c)

Figure 7: The numbers of all key notes in the whole structure: (a) nodes numbers of main load-bearing structure, (b) numbers of main loadbearing structure outer inclined cables, and (c) numbers of secondary load-bearing structure's cable truss.

In addition, the prestress level should be as low as possible when the above requirements are met. Too high prestress level will result in too large internal friction, and it is also difficult to deal with the connection nodes.

The overall goal is as follows: in the state of dead load, the cable forces could perfectly balance the structure dead loads, and the deformation of the whole structure should be natural. The specific target parameters are shown in Table 1.

4.4. Results and Discussion. The numbers of all concerned nodes are shown in Figure 7, and the detailed results are shown in the following table.

As is shown in Table 2 and Figure 8, the maximum downwards deflection of the main bearing structure's inner span strut nodes is $9.6 \mathrm{~mm}$, and the deflection span ratio is $0.09 \%$; The maximum upwards deflection of the main bearing structure's inner span strut nodes is $10.5 \mathrm{~mm}$, and the deflection span ratio is $0.1 \%$; The average upwards deflection of all inner span strut nodes of the main bearing structure's is $1.2 \mathrm{~mm}$, and the average deflection span ratio is $0.09 \%$. This shows that the force-finding target of the main suspension cables with the goal that average vertical displacement of the inner span top strut nodes is $0 \mathrm{~mm}$ is achieved.

From Tables 3 and 4 and Figure 8, it could be found that the maximum displacement of self-anchor stocks end is $0.9 \mathrm{~mm}$ and all vertical deformations of main truss selfanchor stocks end nodes vibrate around zero. These indicate 
TABLE 2: Vertical deformation of top nodes of middle struts of one main truss.

\begin{tabular}{|c|c|c|c|c|c|c|c|}
\hline Node number & 1 & 2 & 3 & 4 & 5 & 6 & Average \\
\hline Vertical deformation $(\mathrm{mm})$ & -9.4 & -2.1 & 10.3 & 10.3 & -2.1 & -9.3 & 1.2 \\
\hline Deflection span ratio & $-0.009 \%$ & $-0.002 \%$ & $0.010 \%$ & $0.010 \%$ & $-0.002 \%$ & $-0.009 \%$ & $0.001 \%$ \\
\hline Node number & 7 & 8 & 9 & 10 & 11 & 12 & Average \\
\hline Vertical deformation (mm) & -9.6 & -2.2 & 10.5 & 10.5 & -2.1 & -9.4 & 1.2 \\
\hline Vertical deflection span ratio & $-0.009 \%$ & $-0.002 \%$ & $0.010 \%$ & $0.010 \%$ & $-0.002 \%$ & $-0.009 \%$ & $0.001 \%$ \\
\hline Node number & 13 & 14 & 15 & 16 & 17 & 18 & Average \\
\hline Vertical deformation (mm) & -9.4 & -2.1 & 10.3 & 10.3 & -2.1 & -9.3 & 1.2 \\
\hline Deflection span ratio & $-0.009 \%$ & $-0.002 \%$ & $0.01 \%$ & $0.010 \%$ & $-0.002 \%$ & $-0.009 \%$ & $0.001 \%$ \\
\hline
\end{tabular}

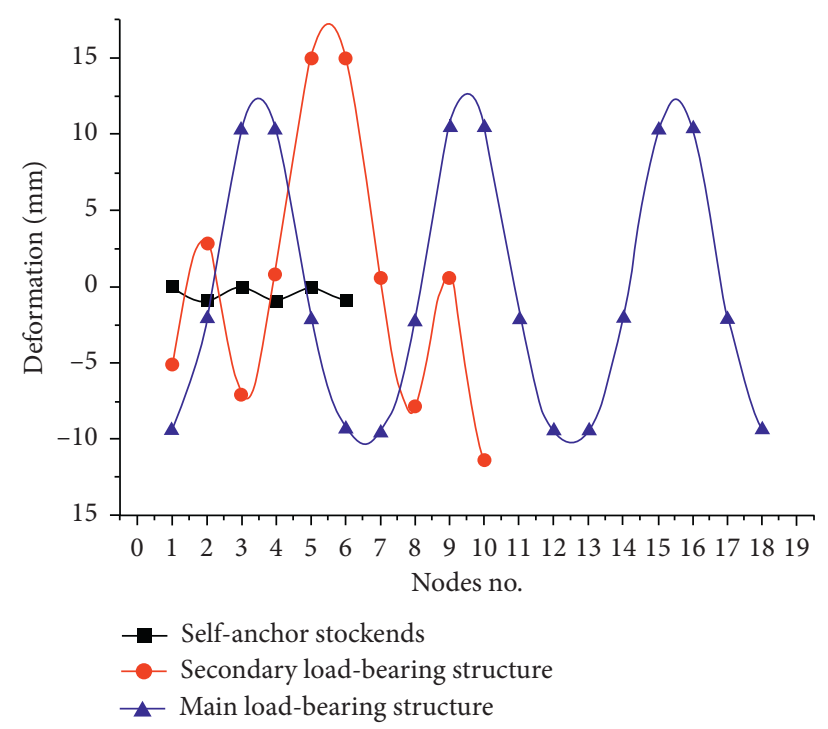

Figure 8: The deformation distributions of all concerned nodes.

TABLE 3: Vertical deformation of main truss self-anchor stocks end nodes.

\begin{tabular}{|c|c|c|c|c|c|c|}
\hline Node number & $e 1(1)$ & $f 1(2)$ & $e 2(3)$ & $f 2(4)$ & $e 3(5)$ & $f 3(6)$ \\
\hline Vertical deformation ( $\mathrm{mm}$ ) & -0.01 & -0.90 & -0.03 & -0.90 & -0.01 & -0.90 \\
\hline
\end{tabular}

TABLE 4: Vertical deformation of midspan node of cable truss of secondary bearing structure.

\begin{tabular}{|c|c|c|c|c|c|}
\hline No. of axial & 1 & 2 & 3 & 4 & 5 \\
\hline Vertical deformation (mm) & -5.1 & 2.9 & -7.1 & 0.8 & 15 \\
\hline No. of axial & 6 & 7 & 8 & 9 & 10 \\
\hline Vertical deformation (mm) & 15 & 0.6 & -7.9 & 0.6 & -11.4 \\
\hline
\end{tabular}

the goal that the vertical displacement of the self-anchor stocks' (SAS) ends is $0 \mathrm{~mm}$ is achieved, which is the forcefinding target of landing vertical cables (MC3). And the vertical displacement of load-bearing cables (C1) of secondary load-bearing structure ranges from $-11.4 \mathrm{~mm}$ to $7.9 \mathrm{~mm}$, and the vertical displacement of $\mathrm{C} 1$ is close to $0 \mathrm{~mm}$, which achieves the goal that the midspan vertical displacement of secondary bearing structure is close to $0 \mathrm{~mm}$.

As it is shown above, the deformation of the top of the main bearing structure strut and the middle span of the secondary bearing structure is very small, almost zero, which can accurately ensure that the position of the structure under the initial cable forces obtained from the force-finding analysis can accurately meet the design and use requirements.

Tables 5 and 6 display that the cable forces of MC2 are $11600 \mathrm{kN}$ and $11700 \mathrm{kN}$, respectively, which have a proper distribution and can meet the expected force-finding goal as listed in Section 4.3. Table 7 indicates that the forces finding the result of side inclined cables (C3) of the secondary load-bearing structure range from $3440 \mathrm{kN}$ to $5840 \mathrm{kN}$, which also have a proper distribution can meet the expected force-finding goal as listed in Section 4.3. Furthermore, Figure 9 directly shows the cable forces distribution of all cables of the secondary load-bearing structure under the action of found initial cable force 
TABLE 5: Main load-bearing structure outer inclined cable forces.

\begin{tabular}{lcc}
\hline Category & No. of cable & Cable force (kN) \\
\hline \multirow{2}{*}{ Outer inclined cable of main load-bearing structure } & $1,3,5$ & 11600 \\
& $2,4,6$ & 11700 \\
\hline
\end{tabular}

TABLE 6: Side inclined cable forces.

\begin{tabular}{llr}
\hline Category & No. & Cable force $(\mathrm{kN})$ \\
\hline 1 & C3 & 4770 \\
2 & C3 & 4680 \\
3 & C3 & 4950 \\
4 & C3 & 4980 \\
5 & C3 & 5060 \\
6 & C3 & 5030 \\
7 & C3 & 5090 \\
8 & C3 & 5020 \\
9 & C3 & 5840 \\
10 & C3 & 3440 \\
\hline
\end{tabular}

TABLE 7: Statistical table of equivalent stress of main load-bearing structure.

\begin{tabular}{lccc}
\hline & Upper chord & Self-anchored stocks & Lower chord \\
\hline Axial force $(\mathrm{kN})$ & $-2038.4 \sim-128.9$ & $-9497.1 \sim-6701.0$ & $-938.4 \sim-302.3$ \\
Equivalent stress $(\mathrm{MPa})$ & $3.0 \sim 56.8$ & $0.0 \sim 175.1$ & $2.0 \sim 88.2$ \\
\hline
\end{tabular}

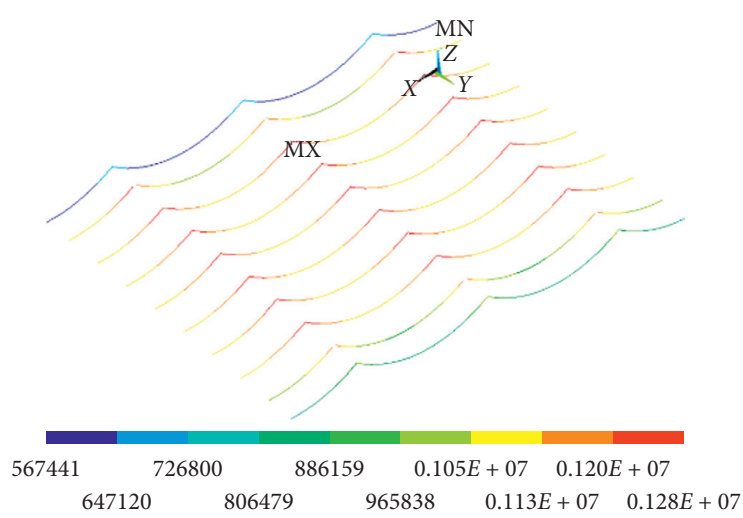

(a)

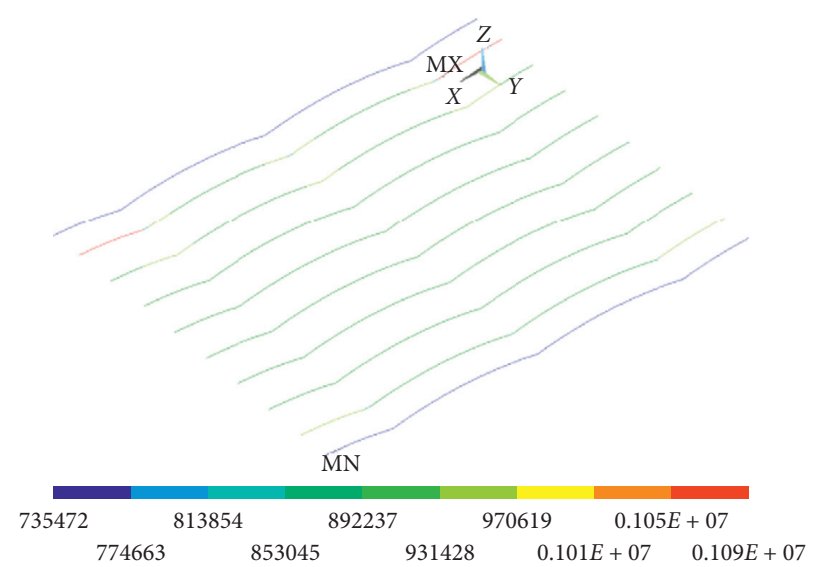

(b)

FIGURE 9: The cable forces distribution of secondary load-bearing structure, (a) the cable forces distribution of load-bearing cables (C1); (b) the cable forces distribution of stable cables (C2).

distribution. It could be directly concluded that, under the action of the found initial cable forces, the inner forces of the same cable type in the whole structure are almost the same, which could make cable design and selection convenient, and reduce the difficulty of cable force control during cable tension construction.

From Table 8 , it can be concluded that the displacement of the main bearing structure is less than $1 / 2000$ of the span of the main bearing structure, and the displacement of the secondary bearing structure is less than $1 / 1000$ of the span of the secondary load-bearing structure. The equivalent stress of the steel structure is 116.1 $\mathrm{MPa}$ and 175.1 $\mathrm{MPa}$, respectively. From Table 7, it can be seen that the internal force of chord and selfanchored stocks of the main bearing structure is $-9497.1 \sim-6701.0 \mathrm{kN}$ and the equivalent stress is $0.0 \sim 175.1 \mathrm{MPa}$, both of which are in the elastic stage. The internal force level of each cable system and the stress level of each component of the whole structure are in a very reasonable state, which shows that, under the action of the initial cable force distribution, each node of the structure has been fully and efficiently exerted. 
TABLE 8: Statistical table of overall deformation and steel structure stress.

\begin{tabular}{|c|c|c|c|c|}
\hline & $\begin{array}{l}\text { Vertical deformation } \\
\qquad(\mathrm{mm})\end{array}$ & $\begin{array}{l}\text { Out-of-plane horizontal } \\
\text { deformation }(\mathrm{mm})\end{array}$ & $\begin{array}{l}\text { In plane horizontal } \\
\text { deformation (mm) }\end{array}$ & $\begin{array}{c}\text { Max equivalent stress } \\
(\mathrm{MPa})\end{array}$ \\
\hline $\begin{array}{l}\text { Main load-bearing } \\
\text { structure }\end{array}$ & $-9.6 \sim 12.2$ & $-5.9 \sim 5.9$ & $-34.0 \sim 34.2$ & 175.1 \\
\hline $\begin{array}{l}\text { Secondary load-bearing } \\
\text { structure }\end{array}$ & $-28.9 \sim 26.3$ & $-22.7 \sim 22.9$ & $-21.5 \sim 21.5$ & 116.1 \\
\hline
\end{tabular}

\section{Conclusions}

In this paper, a new method of force finding called the cumulative expansion force-finding method is proposed for the new type suspension-cable truss composite structure. Firstly, the characteristics of the suspension cable-truss composite structure are discussed (i.e., the deformations of the substructures of suspension cable truss structure are closely related to each other, which means that there is no single independent and stable local substructure). Based on this, a cumulative expansion forcefinding method is proposed. This method can flexibly divide and analyze the substructure according to the force transferring mechanism and structural characteristics, and allow the setting of multiple groups of force finding convergence goals according to different substructures. Finally, based on the actual Shijiazhuang Exhibition Center Exhibition D, the force finding analysis is carried out by using ANSYS finite element software.

The following conclusions could be drawn from the result of the finite element analysis:

(1) Under the action of the found initial cable force distribution, the cable forces of the same cable type are almost the same; the internal force level of each cable system and the stress level of each component of the whole structure are in a very reasonable state, and the deformation of the top of the main bearing structure strut and the middle span of the secondary bearing structure is very small, almost zero, which means that the found initial cable force distribution can fully meet the design and use requirements.

(2) The confusion in the force system during the analysis could be effectively avoided through the setting of multiple substructures and the corresponding convergence conditions, which greatly save the analysis time and improve the accuracy of the force finding analysis.

Therefore, the cumulative expansion force-finding method is suitable for the force finding analysis of suspension-cable truss composite structure.

\section{Data Availability}

The force-finding results and fem model data used to support the findings of this study are included within the article.

\section{Conflicts of Interest}

The authors declare that they have no conflicts of interest.

\section{Acknowledgments}

This work was supported by the Natural Science Foundation of Jiangsu Province, Grant no. BK20190753, and the Natural Science Foundation of the Jiangsu Higher Education Institutions of China no. 18KJB560011.

\section{References}

[1] Q. Ma, M. Ohsaki, Z. Chen, and X. Yan, "Step-by-step unbalanced force iteration method for cable-strut structure with irregular shape," Engineering Structures, vol. 177, pp. 331-344, 2018.

[2] Y. L. Guo, K. Wang, and W. B. Sun, "Research on key structural design problems of the Bao'an stadium," Journal of Building Structures, vol. 34, no. 5, pp. 11-19, 2013.

[3] H. Deng, Y.-Z. Zu, J.-J. Shen, and G. Bai, "Analysis and experiment on erection process of a crescent-shaped cabletruss canopy structure," Journal of Zhejiang University (Engineering Science), vol. 47, no. 3, pp. 488-494, 2013.

[4] M. Kawaguchi, A. Masaru, and I. Tatemichi, "Design, tests and realization of "suspen-dome" system," Journal of the International Association for Shell \& Spatial Structures, vol. 40, no. 131, pp. 179-192, 1999.

[5] M. Kawaguchi, I. Tatemichi, and P. Shan Chen, "Optimum shapes of a cable dome structure," Engineering Structures, vol. 21, no. 8, pp. 719-725, 1999.

[6] M. Kawaguchi, M. Abe, H. Hatato, I. Tatemichi, S. Fujiwara, and H. Matsufuji, "Structural tests on the "suspen-dome" system," in Proceedings of the IASS Symposium, pp. 384-392, Atlanta, Georgia, January 1994.

[7] R. B. Fuller, "Tensile-integrity structures," U.S. Patent, No. 3063521, 1962.

[8] S. Pellegrino and C. R. Calladine, "Matrix analysis of statically and kinematically indeterminate frameworks," International Journal of Solids and Structures, vol. 22, no. 4, pp. 409-428, 1986.

[9] S. Pellegrino, "Structural computations with the singular value decomposition of the equilibrium matrix," International Journal of Solids and Structures, vol. 30, no. 21, pp. 3025-3035, 1993.

[10] R. D. Kangwai and S. D. Guest, "Symmetry-adapted equilibrium matrices," International Journal of Solids and Structures, vol. 37, no. 11, pp. 1525-1548, 2000.

[11] X. Yuan and S. Dong, "Application of integrity feasible prestressing to tensegrity cable domes," China Civil Engineering Journal, vol. 34, no. 2, pp. 33-37, 2001.

[12] J. Lin, S. Dong, Y. Wang, and J. Gao, "Calculation of prestress distribution for large-span cable-strut tensile structures," China Civil Engineering Journal, vol. 39, no. 5, pp. 16-22, 2006.

[13] J. Zhou, W. Chen, B. Zhao, and S. Dong, "A feasible symmetric state of initial force design for cable-strut structures," 
Archive of Applied Mechanics, vol. 87, no. 8, pp. 1385-1397, 2017.

[14] S. Dong and X. Yuan, "A simplified calculation method for initial prestress distribution of sunflower-patterned cable domes," Journal of Building Structures, vol. 25, no. 6, pp. 9-14, 2004.

[15] J. Jorquera-Lucerga, "Form-finding of funicular geometries in spatial arch bridges through simplified force density method," Applied Sciences, vol. 8, no. 12, p. 2553, 2018.

[16] H. J. Schek, "The force density method for form finding and computation of general networks," Computer Methods in Applied Mechanics \& Engineering, vol. 3, no. 1, pp. 115-134, 1974.

[17] M. Vassart and R. Motro, "Multiparametered formfinding method: application to tensegrity systems," International Journal of Space Structures, vol. 14, no. 2, pp. 147-154, 1999.

[18] J. Y. Zhang and M. Ohsaki, "Adaptive force density method for form-finding problem of tensegrity structures," International Journal of Solids \& Structures, vol. 43, no. 18-19, pp. 5658-5673, 2006.

[19] H. C. Tran and J. Lee, "Advanced form-finding for cable-strut structures," International Journal of Solids \& Structures, vol. 47 , no. 14-15, pp. 1785-1794, 2010.

[20] H. C. Tran and J. Lee, "Advanced form-finding of tensegrity structures," Computers \& Structures, vol. 88, no. 3-4, pp. 237-246, 2010.

[21] Y. L. Guo, K. Wang, G. Tian, and B. Zhang, "Research and design of structural form of spoke structure," Journal of Building Structures, vol. 34, no. 5, pp. 1-10, 2013.

[22] M.-M. Ding and B. Luo, "Integral tow-lifting construction technology of a tensile beam-cable dome," Journal of Zhejiang University Science A, vol. 16, no. 12, pp. 935-950, 2015.

[23] H. Kawamura, H. Ohmori, and N. Kito, "Truss topology optimization by a modified genetic algorithm," Structural \& Multidisciplinary Optimization, vol. 23, no. 6, pp. 467-473, 2002.

[24] Z. Wang, X. Yuan, and S. Dong, "Simple approach for force finding analysis of circular geiger domes with consideration of self-weight," Journal of Constructional Steel Research, vol. 66, no. 2, pp. 317-322, 2010.

[25] P. Kjellgren, "A semi-implicit fractional step finite element method for viscous incompressible flows," Computational Mechanics, vol. 20, no. 6, pp. 541-550, 1997.

[26] H. Herrmann and H. Bucksch, Eurocode 3-Design of Steel Structures, Wiley, Hoboken, NJ, USA, 2014. 